\title{
A standardized list of affect-related life events
}

\author{
Dale J. Cohen ${ }^{1} \cdot$ Katherine A. Barker $^{1} \cdot$ Madeline R. White $^{1}$
}

Published online: 4 August 2017

(C) Psychonomic Society, Inc. 2017

\begin{abstract}
In experimental contexts, affect-related word lists have been widely applied when examining how cognitive processes interact with emotional processes. These lists, however, present limitations when studying the relation between emotion and cognitive processes such as time and number processing because affective words do not inherently contain time or quantity information. Live events, in contrast, are experienced by an observer and therefore inherently carry affect information. Unfortunately, existing life-event lists and inventories have been largely applied within clinical contexts as diagnostic tools, and therefore are not suitable for many experimental contexts because they do not contain a balanced number of reliably positive, negative, and neutral life events. In Experiment 1, we create a standardized affect-related lifeevents list with 171 positive, negative, and neutral affectrelated life events. In Experiment 2, we show that strength of affect and significance of the event are integral dimensions, suggesting that these two features are difficult to separate perceptually. The implications of these findings and some potential future applications of the created life-events list are discussed.
\end{abstract}

Keywords Life-event list $\cdot$ Life events $\cdot$ Affect · Depression

Dale J. Cohen

cohend@uncw.edu

1 Department of Psychology, University of North Carolina Wilmington, 601 South College Road, Wilmington, NC 28403-5612, USA

\section{Introduction}

Affect-related word lists have proven useful in experimental research contexts when studying how cognitive processes and emotions interact (Gilboa-Schechtman, Revelle, \& Gotlib, 2000). These same processes may be studied with affective life-event lists. Life events are both personal and episodic, which may provide insights into these processes that individual words cannot capture. However, life-event lists are often used in clinical contexts, rather than experimental contexts, and as such are generally focused on negative or ambiguous events rather than a broader range of affect (Brugha, Bebbington, Tennant, \& Hurry, 1985; Holmes \& Rahe, 1967; Sarason, Johnson, \& Siegel, 1978). Here, we create a standardized life-event list of 171 positive, neutral, and negative events to be used in experimental contexts.

Affect-related word lists have proven useful for examining the relation between emotion and cognitive processes such as attention (Compton, Banich, Mohanty, Milham, Herrington, Miller, Scalf, Webb, \& Heller, 2003), memory (Denny \& Hunt, 1992; Kensinger \& Corkin, 2003; Mackay, Shafto, Taylor, Marian, Abrams, \& Dyer, 2004), face processing (Frühholz, Jellinghaus, \& Herrmann, 2011; Stenberg, Wiking, \& Dahl, 1998), among others. The emotional Stroop test is one example of how affect-related word lists are used to study the relation between emotional state and cognitive performance (for a review, see Williams, Mathews, \& MacLeod, 1996). Similar to the classic Stroop task, the emotional Stroop test requires the participant to identify the font colors of presented words. Unlike the classic Stroop test, the words used in the emotional Stroop relate to various emotional states (i.e., affective words) rather than color. For both versions of the Stroop task, slow reaction times (RTs) and high error rates indicate that the written words significantly interfered with a participant's ability to report font colors. 
The rationale underlying the emotional Stroop test is based upon the supposition that individuals with high state and/or trait affect are hypersensitive to stimuli that corresponds with their emotional state (Williams et al., 1996). This hypersensitivity results in an attentional bias toward mood-congruent stimuli (e.g., depressed individuals would attend to negative affect stimuli) in the external environment. Williams and colleagues (1996) identify two possible effects that may result from this sensitivity towards mood-congruent stimuli. First, hyper-vigilance may boost performance during tasks that involve identifying threatening or concerning stimuli. Second, this sensitivity may also cause considerable distraction during tasks such as the emotional Stroop test, resulting in slower RTs and higher error rates for mood-congruent stimuli relative to mood-incongruent stimuli. Research conducted on the emotional Stroop task has supported this prediction (e.g., Gotlib \& McCann, 1984; Mathews \& MacLeod, 1985). This has been shown in depressed participants (Dudley, O'Brien, Barnett, McGuckin, \& Britton, 2002; Gotlib \& McCann, 1984; Mitterschiffthaler, Williams, Walsh, Cleare, Donaldson, Scott, \& Fu, 2008), participants with anxiety (Lecci \& Cohen, 2007; Lecci \& Cohen, 2002; Mathews \& MacLeod, 1985; Price, Siegle, \& Mohlman, 2012; Richards, French, Johnson, Naparstek, \& Williams, 1992), high trait anger participants (Bertsch, Böhnke, Kruk, \& Naumann, 2009; Eckhardt \& Cohen, 1997), among others. Affective word lists have also been used in word/non-word tasks (e.g., Niedenthal, Halberstadt, \& Setterlund, 1997), memory tasks (e.g., Lewis \& Williams, 1989), brain imaging experiments (e.g., Malhi et. al, 2007), ERP experiments (e.g., Bayer, Sommer, \& Schacht, 2012), and others to study the relation between emotions and cognitive processes.

Similar to affective word lists, affective life-event lists can be used to study the relation between emotion and a variety of cognitive processes (e.g., memory, attention, decision-making, reasoning, etc.). Furthermore, because life events are inherently episodic and experiential (unlike individual words), they may provide unique insights into cognitive processes that affective word lists cannot. For example, research exploring the role of emotion in memory using affective life events may provide qualitatively different results than that using affective words, precisely because of the episodic and experiential nature of life events (e.g., Squire, 2004). In addition, the episodic nature of life events may influence how affective life events can either capture or hold attention relative to that of affective words (e.g., Cabeza, Ciaramelli, Olson, \& Moscovitch, 2008). It is not unreasonable to hypothesize that individuals experiencing specific state or trait emotions may be more influenced by affective life events than affective words because life events are experiential, whereas individual words are generally not. As such, affective life events may provide unique insights into how state or trait emotions interact with cognitive processes. In short, affective life events can be used in the place of affective words in almost all contexts, and such a substitution may provide a unique understanding of the processes being studied. Below, we provide a more detailed example of how an affective life-events list can be used to study the relation between emotion and time/number perception.

Time perception is unique in that it refers to the perception of an abstract yet objectively measureable entity that relates to the perceived duration between events that may occur either in the past (Einstein, 1907) or in the future (time imagination may be a more precise term). Although affective word lists may be used to induce mood (Shevrin, Panksepp, Brakel, \& Snodgrass, 2012), the words themselves do not inherently contain time or quantity information. In contrast, life events are inherently time based because they specifically refer to future and past events that a person may experience in their lifetime. Furthermore, life events are experienced by an observer and therefore inherently carry positive, negative, or neutral emotions. Currently, research examining emotion and time perception focuses on the perception of time while a particular emotion is being experienced (Bar-Haim, Kerem, Lamy, \& Zakay, 2010; Droit-Volet, Fayolle, \& Gil, 2011). Although such a task provides important information, the emotion felt is not integral to the time stimulus. An affective life-events list provides stimuli in which emotion is inherent in the time stimulus.

Number perception is closely tied to many areas of psychology, including time perception. That is, people generally express different time periods using number systems. For example, we may say that an event occurred " 5 months ago," or will occur in " 5 months." Here, time and number are conflated. The conflation of time and number may be more than semantic. Some have proposed that the cognitive mechanisms that measure time are the same as the mechanisms that measure quantity (Oliveri, Vicario, Salerno, Koch, Turriziani, Mangano, Chillemi, \& Caltagirone, 2008; Walsh, 2003). As such, timebased affective stimuli may provide ideal stimuli for studying the relation between number perception and emotion.

Understanding the influence of state and trait emotions on time/number perception is important to understanding both clinical disorders and the cognitive processes underlying time and number perception. Current research presents evidence suggesting that emotion influences one's perceptions of the future when estimating the likelihood of various affectrelated events (see Pyszczynski, Holt, \& Greenberg, 1987). In addition, if emotions influence number perception, this would address the debate as to whether or not people's psychological representation of quantity is abstract (Cohen Kadosh \& Walsh, 2009; McCloskey \& Macaruso, 1995). Furthermore, unlike an affective word, time is not a stimulus that exists in the external environment. Time is entirely a psychological phenomenon, relying on memory and/or projections of the future. Thus, it is unclear how attentional bias would manifest in this context. The above questions can be 
experimentally explored by modifying standard time/number perception tasks to accommodate affective life events. For example, to explore time/number perception, one might modify a simple timeline task. In such a task, the participant is presented a line length representing a month. The participant is then given a target number, say 7 months, and asked to extend the line to the right until it represents the target number (similar to Cohen \& Blanc-Goldhammer's (2011) unbounded number-line). The pattern of errors provides information about the participant's bias in understanding time/number. Affective life events can be incorporated into such a task by tying the numbers to events. For example, the target number can be presented as " $\mathrm{X}$ months until $\mathrm{Y}$ event," where $\mathrm{X}$ is the number and $\mathrm{Y}$ is the affective event (e.g., "7 months until you make a new friend"). If varying the affect associated with the event influences the participant's estimated bias, then one can conclude that affect influences time/number perception. Furthermore, differences between participants' state and trait emotions may also influence the results. In such a paradigm, it is important to have a standardized set of positive, negative, and neutral life events (similar to that of affective word lists). The neutral life events act as a control condition, whereas the positive and negative life events act as experimental conditions.

As illustrated above, for an affective life-events list to effectively be used to assess the relation between emotion and cognitive processes, the list must contain life events that are reliably associated with positive, negative, and neutral emotions. Having such a life-events list allows researchers to counterbalance affect across conditions. In this way, researchers can draw conclusions about the relative influence of different emotions on time and number perception. Current life-event lists, however, were primarily created to assess prior exposure to traumatic events because they are primarily used in clinical contexts and in health research (Dobson, Smith, \& Pachana, 2005). For example, Holmes and Rahe's (1967) Social Readjustment Rating Questionnaire (SRRQ) is an inventory designed to measure the perceived intensity and scale of various life events by assessing an individual's estimated ability to readjust in the wake of an event's aftermath. The SRRQ requires participants to read through the 43 included items and indicate all of the events that they have personally experienced in the recent past (Holmes \& Rahe, 1967; Sarason, Johnson, \& Siegel, 1978). Rather than being a balanced list of positive, negative, and neutral events, almost half of the items in the SSRQ are ambiguous events that could be interpreted as either positive or negative (e.g., major change in the health or behavior of a family member), with most of the remaining items being negative. Life-event lists similar to the SRRQ include the Life Experiences Survey (Sarason, Johnson, \& Seigel, 1978) and the List of Threatening Experiences (Brugha, Bebbington, Tennant, \& Hurry, 1985).The life-event lists developed thus far (generally for clinical purposes) contain many more negative and ambiguous events than positive or neutral life events and are intended to provide general insights regarding the prior experiences of patients and clients. Considering that such assessments are designed to evaluate an individual's mental health status and predicted vulnerability to mental illness, the focus on negative and ambiguous life events is appropriate. The current study addresses a need for a standardized life-events list that contains equal numbers of positive, negative, and neutral affective events and thus can be used in experimental settings. In Experiment 1, we develop a list of 171 affective life events. Because there is evidence that depression level can bias perception of stimuli (e.g., Beck, 1970), we assessed whether participants' level of depression, as measured by the BDI-II, influenced their ratings of the life event's affect. In Experiment 2, we assess the relation between the strength of affect and significance of each life event.

\section{Experiment 1}

In Experiment 1, we develop a list of 171 positive, neutral, and negative life events.

\section{Method}

Participants One hundred and thirty-nine undergraduate students were recruited to participate from the university participant pool in exchange for class credit. Ninety-four of the participants were female and 45 of the participants were male.

Materials All stimuli were presented on a 24-in. LED color screen controlled by a Mac mini. To create an extensive list of future life events, a panel of six researchers came together to generate various life events that were considered to be positive, negative, or neutral. As a result, a list of 258 different life events was created. Eighty-nine of the events were considered to be potentially positive by the researchers, 90 were considered to be potentially negative, and 79 were considered to be potentially neutral. Positive events generated by the researchers included events that were predicted to be seen as enjoyable or something that individuals would look forward to. For example, events such as winning a million dollars, being hired for an ideal job, getting a new car, graduating college, and going on a vacation were included on the list as positive events. Negative events in the list were predicted to be seen as events that individuals might worry about, would not enjoy, or would not look forward to. Examples that were considered to be negative events include losing a job, getting a fatal disease, being struck by lightning, experiencing a large financial loss, and having a loved one die. The events that the researchers considered to be potentially neutral can be described as simple events that do not elicit either positive or negative emotions. For example, events such as going to a 
different store, watching a different TV show, and making a grocery list were included on the list of neutral events.

For each trial, participants were presented with a gray dialogue box in the center of the screen. A randomly selected event was centered at the top of the dialogue box. Directly below the event, participants were presented with a slider used to input their event ratings. The slider subtended $18.5^{\circ}$ visual angle and consisted of a black horizontal line with the left end labeled "extremely negative" and the right end labeled "extremely positive." The "thumb" was not visible until the participant clicked on the slider. This was done so that the starting position of the "thumb" did not influence the participant's rating of the event. Once the participant clicked on the slider, the "thumb" appeared on the horizontal line in the position of the mouse pointer. At that time, the participant could click and drag the "thumb" to the desired position on the slider. When the "thumb" was in the desired positon, the participant was to click the blue "OK" button that was presented below the slider in the dialogue box.

All participants completed the Beck's Depression Inventory II (BDI-II; Beck, Steer, \& Brown, 1996). We removed the question that asked about suicide from the inventory to ease passage through the university Institutional Review Board. We had participants complete the BDI-II to ensure that a relationship did not exist between depression levels and the ratings of events, because such a relationship could influence the interpretation of the events in future experiments.

Procedure Participants completed the experiment in a small dark room with a computer. This is the typical setting for the perceptual experiments run in the laboratory and is intended to reduce potential distractions. At the beginning of the experiment, participants first read the instructions explaining the task.

Participants then completed three practice trials that were identical to the experimental trials. After completing the three practice trials, participants began the formal experiment. For each trial, participants were presented with the dialogue box containing the presented event and rating scale, as described above. The participant's task was to rate the event based on how it made them "feel" using a scale ranging from "extremely negative" to "extremely positive." Participants made their responses by clicking on the horizontal line, which caused a small vertical bar to appear on the rating scale. Participants were able to click and drag the vertical bar along the scale to make their ratings. Once the participant dragged the vertical bar to the location on the scale that accurately reflected their rating, responses were submitted by clicking the "OK" button located under the rating scale. As such, there was no time limit for the participant to make his or her response. Once the response was submitted, the next trial began until all 258 trials were completed. Halfway through the experiment, participants had one selftimed break. The order of the 258 life events was randomized between participants. Once all trials were completed, participants then completed the BDI-II.

\section{Results}

Two male participants did not complete all of the trials and were excluded from data analysis. The placement of the vertical bar on the horizontal rating scale was converted to a value ranging from 0 to 1,000 , where "extremely negative" on the scale represented a value of 0 and "extremely positive" represented a value of 1,000 . The intervening values were assigned based on the linear distance between the two endpoints. All converted values were rounded to the nearest whole number.

To remove participant response bias, we standardized each participant's ratings of the 258 presented events. As a result, each participant's set of ratings had a mean of 0 and a standard deviation of 1 . Ratings for each event were collapsed across subjects and the mean and standard deviation for each of the 258 events were calculated. Events with standard deviations over .6 were removed from further analysis. This was done to eliminate events that were difficult to classify, as suggested by large variances in ratings. This criterion removed a total of fourevents. We performed a Cronbach's alpha to test the inter-rater reliability of the ratings. Participants' ratings were found to be highly reliable with an alpha of 0.99 .

We classified the 57 events with the highest mean affect ratings as the positive events to be used in our affective lifeevents list. Similarly, we classified the 57 events with the lowest mean affect ratings as the negative events to be used in our affective life-events list. Finally, we classified the 57 events whose absolute value of the mean affect ratings were closest to 0 as the neutral events to be used in our affective life-events list. All other events were not used in our final affective lifeevents list and were discarded. By discarding the life events that were rated between categories, we mitigate the probability that the life events in our list will be perceived with equivocal affect. Figure 1 presents the average affect rating of all 258 life events and highlights those events that were used in the list and those that were discarded. The Appendix contains the standardized ratings and the events in the final life-events list.

To assess whether there was a relationship between participants' ratings of the events and their level of depression, we tested whether participants' BDI scores predicted their deviations from the average rating in each of the three affect conditions (positive, negative, and neutral). That is, if depression levels influence ratings, then one might expect participants who score high on the BDI to rate positive events as slightly less positive than those who score low on the BDI. The opposite might be true for the negative events. To assess this, we first calculated the non-standardized mean values for each event in the final life-events list. Using these mean values, we then calculated the average rating for each affect condition 


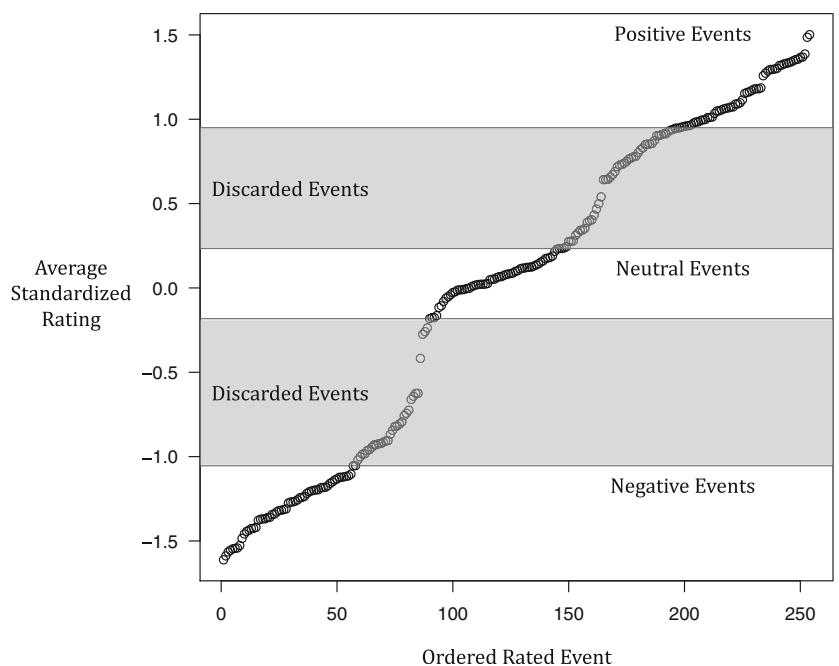

Fig. 1 Distribution of means for rated events. The graph depicts the means, in order from least to greatest, for all 258 events presented to participants. The 57 events with the lowest average standard ratings were identified as negative events. The 57 events with average standard ratings closest to 0 were identified as the neutral events. The 57 events with the highest average standard ratings were identified positive events. Events that fall within the "Discarded" regions of the graph were eliminated from the final event list to ensure that all life events chosen for the final list were clearly and consistently representative of the intended valences

(the 57 positive events, the 57 negative events, and the 57 neutral events). These three averaged values gave us a mean rating for each type of valence. Next, we calculated each participant's average, non-standardized rating for the 57 positive, negative, and neutral events. Finally, we calculated each participant's deviation score by subtracting the overall mean rating from the participant's mean rating for each valence condition. This calculation indicated how each participant's ratings differed from the overall group average. To assess whether depression influenced event ratings, we performed a correlation between these difference scores and BDI scores for each valence condition. If, for example, depressive individuals (as identified by high BDI scores) rated positive events as less positive than non-depressive individuals, we would predict a negative correlation between BDI score and the calculated difference score described above. The results showed that, for each valence, there was no significant relation between depression levels and the difference in means (using a Bonferroni corrected alpha for three tests, $p>0.017$ ).

\section{Discussion}

In Experiment 1, we identified 171 life events that are reliably associated with positive, negative, and neutral event valences. The 57 life events identified as having a positive valence reflect personal achievement, wealth, success, and good fortune. The 57 life events identified as having a negative valence reflect illness, failures, loss, and financial ruin. The 57 life events identified as having a neutral valence reflect commonplace, day-to-day activities and minor deviations from the norm (e.g., "make a sandwich with different bread"). Although the 171 positive, negative, and neutral life events identified here reliably convey the intended emotional valence, emotional valence may not be the only factor that distinguishes the groups. Specifically, the life events identified as having a positive and negative valence largely signify important or significant developments within a person's life. In contrast, the life events identified as having a neutral valence signify seemingly trivial developments within a person's life. To explore the relationship between event valence and event significance, we conducted a second experiment that assessed participants' perceptions of significance of the life events.

\section{Experiment 2}

In Experiment 2, participant ratings of event significance were acquired for all 258 life-event statements originally developed in Experiment 1. It was expected that event valence would be closely correlated with event significance, with emotional (positive and negative) events considered as significant and neutral events considered as insignificant. To determine whether level of depression significantly influences perceptions of event significance, all participants also took the BDI-II.

\section{Method}

Participants. One hundred and three undergraduate students were recruited to participate from the university participant pool in exchange for class credit. Sixty-five of the participants were female, 37 of the participants were male, and one participant did not respond.

Materials. Although a subset of 171 events was chosen from the original 258 life events in Experiment 1 to be included in the final life-events list, significance ratings were collected for all 258 original life events. As such, all materials and stimuli used in Experiment 2 were identical to Experiment 1 with the following exception: In Experiment 2, participants rated event significance using a slider that consisted of a black horizontal line with the end bounds labeled "extremely insignificant" to "extremely significant."

Procedure. Procedures followed in Experiment 2 were identical to those of Experiment 1.

\section{Results}

Three participants' data were removed from the analysis because they did not understand the instructions. These 
participants' average significance rating for neutral events (e.g., "watch a different TV show") were higher than their average significance rating of negative events (e.g., "have your child die"). The remaining participants' responses in Experiment 2 were standardized using the same procedure as Experiment 1. Significance ratings for each event were collapsed across subjects and the mean and standard deviation for each of the original 258 events were calculated. Means and standard deviations for the significance ratings of the 171 life events chosen in Experiment 1 are included in the Appendix. We performed a Cronbach's alpha to test the inter-rater reliability of the significance ratings. Participants' ratings were found to be highly reliable with an alpha of 0.996 . We assessed the relation between significance ratings of the positive, negative, and neutral events (as identified in Experiment 1) and BDI scores using the same procedure as Experiment 1. The results showed that, for each valence, there was no significant relation between depression levels and the difference in means.

To assess the relation between life-event valence and lifeevent significance, we computed a correlation between the absolute values of the average standardized event valence ratings and the average standardized event significance. Computing the absolute values of standardized valence ratings was necessary because we hypothesized that valence strength was correlated with event significance, not valence direction. That is, both highly negative life events (which had negative event valences) and highly positive life events (which had positive valences) should be highly significant. The correlation for all original 258 items revealed a significant correlation between event valence and event significance that was near perfect, $\mathrm{r}=.957, p<.05$. Similar correlational results were found for the final 171 items, $\mathrm{r}=.98, p<.05$.

\section{Discussion}

The results of Experiment 2 are clear: strength of emotional valence is virtually indistinguishable from event significance. This result is interesting because it suggests that emotional strength and significance are integral dimensions (see Garner, 1976). We discuss this finding in the General discussion.

\section{General discussion}

Here, we created a standardized, affective life-event list that contains an equal number of positive, negative, and neutral events. In Experiment 1, we asked participants to rate 258 life events on a continuous scale from extremely positive to extremely negative. We then standardized the ratings within participants and averaged the standardized ratings across participants. Using the calculated average rating for each event, we then classified the 57 with the lowest averages as the negative events, the 57 with the highest averages as the positive events, and the 57 averages centered around 0 as the neutral events. In Experiment 2, we explored the relationship between event valence and event significance. To do this, we asked a novel set of participants to rate all 258 original life events on a continuous scale ranging from extremely insignificant to extremely significant. The results revealed that event valence strength was almost perfectly correlated with event significance.

The results from both experiments demonstrated that there was very high inter-rater reliability, suggesting that participants rated each event very similarly. Additionally, the results did not reveal an effect for depression across event valence or event significance. Therefore, it can be assumed that depressive and non-depressive participants perceive the valence and significance of each event similarly. These combined results indicate that we have created a robust list of life events categorized by valence that can be used in experimental situations.

The life events that were included in the final life-events list encompass a diverse array of events that range from highly desirable events to intensely traumatic events. In the final event list, "have your child die" was the most negatively rated life event and "cure cancer" was the most positively rated life event. The neutral life events were those with standardized ratings closest to zero, such as "type on a different computer." Importantly, we discarded the 87 life events that fell between the categories (see Fig. 1). This resulted in a reliable list of clearly affective events.

Predictably, many of the events chosen as positive events either involved aspects of high monetary value (i.e., getting a large bonus at work) or of winning or receiving something for free (i.e., winning a new Porsche or getting a free plane ticket to go anywhere). Positive events with the highest averages typically revolved around personal life events or accomplishments, such as watching your child walk for the first time or finding your ideal significant other. These types of events reflected highly desirable life events that veered away from the appeal of materialistic gain in favor of more sentimental and relational rewards.

Many of the negative events chosen for the final list carry negative connotations of physical harm, referencing health issues, injury, or death to either oneself or close others (i.e., getting a fatal disease or having a loved one die). In the final list, there are also several negative events that suggest detrimental developments within the context of an individual's personal life (i.e., being in an unhappy relationship or discovering that your spouse is having an affair). Contrasting the deeply personal nature of the negative life events referenced above, other negative events primarily revolved around the loss of monetary or material wealth (i.e., go bankrupt, total your car, or lose your life savings in the stock market).

Near the center of the life-event list continuum are neutral events that were not rated to be extremely negative or extremely positive. Events within this valence category generally 
reflect commonplace activities that may often be expected to occur from day to day. Many neutral event items involve engaging in a variety of relatively simple and familiar tasks, such as using a calculator or making a grocery list. The majority of these tasks seem to require little attention, time, and energy, and involve activities that are largely automatic to most (such as tying your shoe or raising your hand). Other tasks within this valence category include subtle cues that suggest neutrality (i.e., references to neutral colors - "hang up a tan towel") or only slight, inconsequential deviations from one's normal behaviors or activities (i.e., "make a sandwich with different bread" or "browse on a different website").

The robust correlation between event valence and event triviality suggests that event valence and event significance are integral dimensions that jointly influence how specific life events are perceived. Garner (1976) describes integral dimensions as dimensions of a stimulus that may not be meaningfully perceived independently from one another. This contrasts with separable dimensions, which can be perceived independently of one another. To illustrate, consider color. Color is composed of brightness, hue, and saturation. Though these three features can be manipulated independently of one another, they are not perceived independently of one another. Indeed, it is only with extreme effort that a perceiver can identify each of the three features separately. As such, hue, brightness, and saturation are said to be integral dimensions. In contrast, the color and shape of an object are said to be separable dimensions because they can be readily perceived independently of one another.

In the same way that the dimensions of hue, saturation, and brightness are inextricably linked in the example above, findings from the current study suggest that event valence strength and event significance are linked. The interdependent nature of these two life event features (valence and significance) is intuitive, given that positive and negative events inherently possess emotional content that directly impact the individual. Thus, in relation to neutral events, which are characterized by their uneventfulness and triviality, positive and negative events are intrinsically significant because they carry with them the potential to alter one's life and/or livelihood. This suggests that one cannot generate highly significant, neutral life events. This prediction, however, requires further research.

Due to the nature of the proposed life-event list (a list containing events ranging from some of the very best to some of the very worst events that a person may experience), we explored whether individual biases would influence life-event ratings. Specifically, we assessed whether depression scores influenced event ratings. The rationale behind this analysis is based on the robust finding that depressed individuals display a characteristic negativity bias that significantly impacts one's perceptions and cognitions about themselves, others, and the world around them (Beck, 1970). Furthermore, non-depressed individuals have been shown to demonstrate characteristic optimistic biases that significantly impact their judgments and decision-making processes (i.e., rating the probability that events will occur to themselves vs. to others) (Pyszczynski et al., 1987). If level of depression influences the perceived valence or significance of life events, then this discovery would complicate our event-rating interpretations, adding ambiguity to the process of interpreting and standardizing the ratings attained. Fortunately, there was not a significant relation between depression levels and event valence or significance ratings.

The life-event list developed in the current study is intended for experimental applications; however, this list may also be used to develop useful clinical tools. For example, one potential use for the current life-event list involves modifying the list to create a comprehensive life-experiences inventory that addresses the concerns of Donoghue, TravissTurner, House, Lewis, and Gilbody (2016). These concerns are directed at the disadvantages of self-report questionnaires relative to interview methods when assessing clients' life experiences. Historically, interview techniques have been the preferred administration method when issuing assessments and working with clinical patients because they provide opportunities for professionals to offer insights that supplement the interviewee's responses. However, because of the resources required to complete an interview, larger clinical studies have begun leaning towards briefer, more streamlined inventories and questionnaires (Donoghue et al., 2016). Donoghue and colleagues (2016) found that, although both questionnaires and interviews captured a similar pattern of life event experiences, the questionnaire method was too general and lacked the ability to capture finer details. Some of the advantages of the current life-event list include the expansive array of event items and the balance of positive, negative, and neutral event items that the list offers. These advantages provide a foundation from which one can develop an inventory or questionnaire that documents a thorough, balanced, and representative historical account of a client's former experiences. Furthermore, the neutral event items may uniquely serve as helpful validity checks that are sensitive to careless responding.

Within less structured and more open-ended interview contexts, the current life-events list may prove useful as a foundation for a coding tool that allows clinicians, researchers, or other professionals to readily document life event experiences - and their affect - that are reported by patients or subjects. The current life-event list may also serve as a foundation for intervention in clinical settings and mood induction in experimental settings. For example, clinicians and researchers may induce positive moods by asking clients/participants to imagine the positive events in the list. The neutral list may serve researchers well as a stimulus for a control condition. 
The possible uses of the affective life-events list described above illustrate only a few of the many potential uses of the list developed in the current study. However, more research is needed to explore these and other possibilities.

In sum, the primary goal of the current study was to develop a standardized list of affective life events that could then be used for future research. We developed a standardized life-event list that encompasses three major event valences (positive, negative, and neutral). In the course of this research we discovered that event significance and event valence strength are likely integral dimensions. It is our hope that future research will use our newly established life-event list to study the relation between cognitive and perceptual processes (such as time and number perception) and state and trait emotions and to potentially develop new clinical tools.

\section{Appendix}

Table 1 List of life events

\begin{tabular}{|c|c|c|c|c|c|}
\hline \multirow[b]{2}{*}{ Event } & \multicolumn{3}{|c|}{$\begin{array}{l}\text { Event } \\
\text { valence }\end{array}$} & \multicolumn{2}{|c|}{$\begin{array}{l}\text { Event } \\
\text { significance }\end{array}$} \\
\hline & Mean & SD & Valence & Mean & SD \\
\hline Have your child die & -1.612 & 0.239 & Negative & 1.343 & 0.477 \\
\hline Watch your best friend die & -1.588 & 0.246 & Negative & 1.309 & 0.537 \\
\hline $\begin{array}{l}\text { Experience your mother's } \\
\text { death }\end{array}$ & -1.565 & 0.255 & Negative & 1.265 & 0.533 \\
\hline $\begin{array}{l}\text { Have your sibling attempt } \\
\text { suicide }\end{array}$ & -1.555 & 0.228 & Negative & 1.330 & 0.304 \\
\hline $\begin{array}{l}\text { Experience your } \\
\text { father's death }\end{array}$ & -1.547 & 0.343 & Negative & 1.246 & 0.494 \\
\hline $\begin{array}{l}\text { Experience your } \\
\text { sibling's death }\end{array}$ & -1.544 & 0.283 & Negative & 1.348 & 0.406 \\
\hline Have a loved one die & -1.542 & 0.209 & Negative & 1.300 & 0.378 \\
\hline Be murdered & -1.527 & 0.316 & Negative & 1.198 & 0.719 \\
\hline $\begin{array}{l}\text { Find out your parent } \\
\text { is diagnosed with } \\
\text { Alzheimer's }\end{array}$ & -1.485 & 0.237 & Negative & 1.146 & 0.421 \\
\hline $\begin{array}{l}\text { Get dumped on your } \\
\text { wedding day }\end{array}$ & -1.459 & 0.337 & Negative & 1.179 & 0.452 \\
\hline $\begin{array}{l}\text { Discover your spouse is } \\
\text { having an affair }\end{array}$ & -1.443 & 0.199 & Negative & 1.060 & 0.516 \\
\hline Get a fatal disease & -1.436 & 0.286 & Negative & 1.176 & 0.459 \\
\hline Attend a friend's funeral & -1.426 & 0.373 & Negative & 1.184 & 0.376 \\
\hline Be diagnosed with cancer & -1.425 & 0.249 & Negative & 1.199 & 0.402 \\
\hline Go blind & -1.420 & 0.320 & Negative & 1.148 & 0.499 \\
\hline $\begin{array}{l}\text { Have your home destroyed } \\
\text { by a tornado }\end{array}$ & -1.377 & 0.231 & Negative & 1.037 & 0.394 \\
\hline $\begin{array}{l}\text { Lose all of your belongings } \\
\text { in a house fire }\end{array}$ & -1.371 & 0.197 & Negative & 0.993 & 0.468 \\
\hline Go bankrupt & -1.369 & 0.254 & Negative & 0.929 & 0.515 \\
\hline Be in a plane crash & -1.369 & 0.235 & Negative & 1.025 & 0.508 \\
\hline Have a heart attack & -1.361 & 0.248 & Negative & 1.055 & 0.427 \\
\hline $\begin{array}{l}\text { Lose your life savings } \\
\text { in the stock market }\end{array}$ & -1.360 & 0.261 & Negative & 1.029 & 0.514 \\
\hline Be convicted of a felony & -1.343 & 0.251 & Negative & 0.894 & 0.59 \\
\hline
\end{tabular}

Table 1 (continued)

Event

Event

valence

significance

Lose an arm

Witness a murder

Have your home foreclosed

Get shot

Be committed to a mental institution

Get fired from your ideal job

Be evicted from your home

Have your car stolen

Fail a class

Have a pet die

Get a divorce

Total your car

Die

Lose your job

Be attacked by a shark

Get arrested

Experience a large financial loss

Be a victim of a mugging

Fall from a balcony

$\mathrm{Be}$ in an unhappy relationship

Be struck by lightning

Be stuck in a boring, unfulfilling job

Your parents getting divorced

Get sued

Get in a car wreck

Become infertile

Get alcohol poisoning

Have your credit card stolen

Be rejected from your ideal school

Be wrongfully accused of something

Be injured in a car accident

Lose important files because your computer crashes

Lose a friendship

Fail a test

Spend the holidays alone

Sit in a different chair

Change your voicemail

Lock a French door

Move a chair

Walk down different stairs

Count change

Hang up a tan towel

Scratch your left arm

Button your tan shirt

Turn on windshield wipers

Double check the time

Tie your shoe

Close a mini refrigerator

Wear tan pants

Turn on a different computer

Get into a tan car

Type on a different computer

Brush your hair with a different hairbrush

Open a duffle bag

Sit at a different desk

Feed your pet different food

Stand up on a stool $\begin{array}{lllll}-1.340 & 0.268 & \text { Negative } & 1.060 & 0.510\end{array}$

$\begin{array}{lllll}-1.328 & 0.416 & \text { Negative } & 1.137 & 0.426\end{array}$

$\begin{array}{lllll}-1.320 & 0.245 & \text { Negative } & 0.861 & 0.521\end{array}$

$\begin{array}{lllll}-1.318 & 0.318 & \text { Negative } & 0.962 & 0.571\end{array}$

$\begin{array}{lllll}-1.314 & 0.347 & \text { Negative } & 0.882 & 0.628\end{array}$

$\begin{array}{lllll}-1.310 & 0.344 & \text { Negative } & 0.788 & 0.576\end{array}$

$\begin{array}{lllll}-1.275 & 0.306 & \text { Negative } & 0.909 & 0.398\end{array}$

$\begin{array}{lllll}-1.269 & 0.264 & \text { Negative } & 0.718 & 0.463\end{array}$

$\begin{array}{lllll}-1.268 & 0.288 & \text { Negative } & 0.567 & 0.567\end{array}$

$\begin{array}{lllll}-1.263 & 0.325 & \text { Negative } & 0.847 & 0.545\end{array}$

$\begin{array}{lllll}-1.256 & 0.423 & \text { Negative } & 0.927 & 0.500\end{array}$

$\begin{array}{lllll}-1.243 & 0.317 & \text { Negative } & 0.750 & 0.431\end{array}$

$\begin{array}{lllll}-1.241 & 0.584 & \text { Negative } & 1.197 & 0.626\end{array}$

$\begin{array}{lllll}-1.235 & 0.258 & \text { Negative } & 0.797 & 0.447\end{array}$

$\begin{array}{lllll}-1.218 & 0.377 & \text { Negative } & 0.813 & 0.586\end{array}$

$\begin{array}{lllll}-1.208 & 0.274 & \text { Negative } & 0.723 & 0.568\end{array}$

$\begin{array}{lllll}-1.203 & 0.248 & \text { Negative } & 0.797 & 0.431\end{array}$

$\begin{array}{lllll}-1.199 & 0.262 & \text { Negative } & 0.735 & 0.418\end{array}$

$\begin{array}{lllll}-1.197 & 0.295 & \text { Negative } & 0.642 & 0.640\end{array}$

$\begin{array}{lllll}-1.196 & 0.274 & \text { Negative } & 0.510 & 0.510\end{array}$

$\begin{array}{lllll}-1.184 & 0.371 & \text { Negative } & 0.906 & 0.545\end{array}$

$\begin{array}{lllll}-1.183 & 0.346 & \text { Negative } & 0.382 & 0.747\end{array}$

$\begin{array}{lllll}-1.182 & 0.491 & \text { Negative } & 0.966 & 0.467\end{array}$

$\begin{array}{lllll}-1.172 & 0.266 & \text { Negative } & 0.721 & 0.393\end{array}$

$\begin{array}{lllll}-1.158 & 0.283 & \text { Negative } & 0.681 & 0.470\end{array}$

$\begin{array}{lllll}-1.150 & 0.434 & \text { Negative } & 0.824 & 0.685\end{array}$

$\begin{array}{lllll}-1.138 & 0.303 & \text { Negative } & 0.514 & 0.551\end{array}$

$\begin{array}{lllll}-1.133 & 0.312 & \text { Negative } & 0.579 & 0.503\end{array}$

$\begin{array}{lllll}-1.122 & 0.403 & \text { Negative } & 0.539 & 0.553\end{array}$

$\begin{array}{lllll}-1.122 & 0.322 & \text { Negative } & 0.562 & 0.594\end{array}$

$\begin{array}{lllll}-1.120 & 0.296 & \text { Negative } & 0.720 & 0.512\end{array}$

$\begin{array}{lllll}-1.117 & 0.337 & \text { Negative } & 0.598 & 0.517\end{array}$

$\begin{array}{lllll}-1.114 & 0.323 & \text { Negative } & 0.610 & 0.454\end{array}$

$\begin{array}{lllll}-1.103 & 0.309 & \text { Negative } & 0.231 & 0.594\end{array}$

$\begin{array}{lllll}-1.054 & 0.402 & \text { Negative } & 0.369 & 0.681\end{array}$

$\begin{array}{lllll}-0.003 & 0.227 & \text { Neutral } & -1.300 & 0.379\end{array}$

$\begin{array}{lllll}-0.003 & 0.261 & \text { Neutral } & -1.181 & 0.353\end{array}$

$\begin{array}{lllll}0.007 & 0.319 & \text { Neutral } & -1.118 & 0.502\end{array}$

$\begin{array}{lllll}-0.008 & 0.178 & \text { Neutral } & -1.345 & 0.403\end{array}$

$\begin{array}{lllll}-0.011 & 0.267 & \text { Neutral } & -1.291 & 0.330\end{array}$

$\begin{array}{lllll}-0.011 & 0.384 & \text { Neutral } & -1.096 & 0.506\end{array}$

$\begin{array}{lllll}0.013 & 0.162 & \text { Neutral } & -1.290 & 0.435\end{array}$

$\begin{array}{lllll}-0.013 & 0.277 & \text { Neutral } & -1.290 & 0.399\end{array}$

$\begin{array}{lllll}0.018 & 0.200 & \text { Neutral } & -1.354 & 0.369\end{array}$

$\begin{array}{lllll}0.020 & 0.325 & \text { Neutral } & -1.019 & 0.587\end{array}$

$\begin{array}{lllll}0.022 & 0.256 & \text { Neutral } & -1.032 & 0.565\end{array}$

$\begin{array}{lllll}0.022 & 0.222 & \text { Neutral } & -1.181 & 0.455\end{array}$

$\begin{array}{lllll}0.023 & 0.176 & \text { Neutral } & -1.300 & 0.405\end{array}$

$\begin{array}{lllll}-0.023 & 0.334 & \text { Neutral } & -1.304 & 0.387\end{array}$

$\begin{array}{lllll}0.027 & 0.203 & \text { Neutral } & -1.253 & 0.363\end{array}$

$\begin{array}{lllll}-0.027 & 0.204 & \text { Neutral } & -1.297 & 0.384\end{array}$

$\begin{array}{lllll}-0.041 & 0.278 & \text { Neutral } & -1.201 & 0.387\end{array}$

$\begin{array}{lllll}0.048 & 0.281 & \text { Neutral } & -1.206 & 0.351\end{array}$

$\begin{array}{lllll}0.052 & 0.224 & \text { Neutral } & -1.279 & 0.412\end{array}$

$\begin{array}{lllll}-0.052 & 0.304 & \text { Neutral } & -1.182 & 0.412\end{array}$

$\begin{array}{lllll}0.052 & 0.285 & \text { Neutral } & -0.970 & 0.423\end{array}$

$\begin{array}{lllll}-0.061 & 0.329 & \text { Neutral } & -1.126 & 0.464\end{array}$ 
Table 1 (continued)

\begin{tabular}{|c|c|c|c|c|c|}
\hline \multirow[b]{2}{*}{ Lay down on a different couch } & \multicolumn{3}{|l|}{$\begin{array}{l}\text { Event } \\
\text { valence }\end{array}$} & \multicolumn{2}{|c|}{$\begin{array}{l}\text { Event } \\
\text { significance }\end{array}$} \\
\hline & 0.061 & 0.224 & Neutral & -1.172 & 0.371 \\
\hline Replace a lightbulb & 0.067 & 0.297 & Neutral & -1.108 & 0.517 \\
\hline Browse on a different website & 0.067 & 0.240 & Neutral & -1.138 & 0.454 \\
\hline Raise your hand & 0.074 & 0.248 & Neutral & -1.114 & 0.427 \\
\hline Put ice in a cup & 0.080 & 0.233 & Neutral & -1.238 & 0.507 \\
\hline Carry a duffle bag & -0.080 & 0.260 & Neutral & -1.276 & 0.341 \\
\hline Use a calculator & 0.083 & 0.311 & Neutral & -1.010 & 0.567 \\
\hline Turn on a flashlight & 0.086 & 0.245 & Neutral & -1.170 & 0.495 \\
\hline $\begin{array}{l}\text { Make a sandwich with } \\
\text { different bread }\end{array}$ & 0.089 & 0.286 & Neutral & -1.169 & 0.433 \\
\hline Put on a different coat & 0.098 & 0.225 & Neutral & -1.155 & 0.403 \\
\hline Staple a document & 0.102 & 0.236 & Neutral & -1.280 & 0.425 \\
\hline Make your bed in a hurry & -0.106 & 0.274 & Neutral & -1.140 & 0.451 \\
\hline $\begin{array}{l}\text { Wash your hands with } \\
\text { different soap }\end{array}$ & 0.113 & 0.221 & Neutral & -1.226 & 0.397 \\
\hline Sit on a bus & -0.115 & 0.333 & Neutral & -1.155 & 0.396 \\
\hline Erase a white board & 0.117 & 0.312 & Neutral & -1.268 & 0.453 \\
\hline Cross an empty street & 0.118 & 0.266 & Neutral & -1.202 & 0.450 \\
\hline Cut your nails & 0.122 & 0.277 & Neutral & -1.121 & 0.444 \\
\hline Go to a different store & 0.123 & 0.245 & Neutral & -1.069 & 0.389 \\
\hline $\begin{array}{l}\text { Put the flag up on your } \\
\text { mailbox }\end{array}$ & 0.124 & 0.260 & Neutral & -0.965 & 0.487 \\
\hline Open a door & 0.130 & 0.264 & Neutral & -1.188 & 0.466 \\
\hline $\begin{array}{l}\text { Go driving in a different } \\
\text { neighborhood }\end{array}$ & 0.136 & 0.341 & Neutral & -1.078 & 0.486 \\
\hline $\begin{array}{l}\text { Wash your hair with different } \\
\text { conditioner }\end{array}$ & 0.143 & 0.297 & Neutral & -1.169 & 0.336 \\
\hline $\begin{array}{l}\text { Go walking in a different } \\
\text { neighborhood }\end{array}$ & 0.154 & 0.320 & Neutral & -0.964 & 0.491 \\
\hline Make a grocery list & 0.161 & 0.273 & Neutral & -0.869 & 0.559 \\
\hline Resend an email & -0.164 & 0.305 & Neutral & -1.003 & 0.435 \\
\hline $\begin{array}{l}\text { Take a shower with different } \\
\text { shampoo }\end{array}$ & 0.174 & 0.358 & Neutral & -1.183 & 0.376 \\
\hline Turn off the television by hand & -0.176 & 0.283 & Neutral & -1.255 & 0.409 \\
\hline Set your alarm & -0.176 & 0.420 & Neutral & -0.641 & 0.812 \\
\hline Write your name & 0.177 & 0.301 & Neutral & -1.005 & 0.678 \\
\hline Drink flavored water & 0.181 & 0.433 & Neutral & -1.170 & 0.464 \\
\hline Resend a text message & -0.182 & 0.285 & Neutral & -1.050 & 0.497 \\
\hline Watch a different TV show & 0.189 & 0.281 & Neutral & -0.997 & 0.488 \\
\hline Sit on a bench & 0.217 & 0.311 & Neutral & -1.071 & 0.555 \\
\hline Start your friend's car & 0.230 & 0.302 & Neutral & -0.835 & 0.620 \\
\hline Get a pair of socks & 0.234 & 0.342 & Neutral & -1.105 & 0.526 \\
\hline Celebrate your birthday & 0.950 & 0.340 & Positive & 0.236 & 0.547 \\
\hline $\begin{array}{l}\text { Find a large sum of money } \\
\text { on the ground }\end{array}$ & 0.954 & 0.414 & Positive & 0.412 & 0.499 \\
\hline Hit your ideal weight & 0.957 & 0.450 & Positive & 0.378 & 0.542 \\
\hline Watch the sunset & 0.961 & 0.393 & Positive & -0.199 & 0.638 \\
\hline Receive a genuine thank you & 0.962 & 0.339 & Positive & 0.218 & 0.521 \\
\hline Get a paycheck & 0.967 & 0.357 & Positive & 0.346 & 0.551 \\
\hline Get a new car & 0.978 & 0.351 & Positive & 0.468 & 0.427 \\
\hline Go on a cruise & 0.984 & 0.406 & Positive & 0.090 & 0.644 \\
\hline Get your driver's license & 0.984 & 0.326 & Positive & 0.637 & 0.354 \\
\hline Adopt a child & 0.993 & 0.527 & Positive & 1.144 & 0.346 \\
\hline Quit smoking & 0.997 & 0.561 & Positive & 0.856 & 0.568 \\
\hline Get a new house & 0.998 & 0.335 & Positive & 0.741 & 0.444 \\
\hline $\begin{array}{l}\text { Receive a genuine } \\
\text { compliment }\end{array}$ & 1.010 & 0.324 & Positive & 0.228 & 0.564 \\
\hline $\begin{array}{l}\text { Be thrown a surprise } \\
\text { birthday party }\end{array}$ & 1.011 & 0.343 & Positive & 0.231 & 0.589 \\
\hline Become the boss & 1.013 & 0.420 & Positive & 0.760 & 0.446 \\
\hline Go on a trip with friends & 1.034 & 0.323 & Positive & 0.354 & 0.521 \\
\hline Go on an ideal date & 1.049 & 0.320 & Positive & 0.445 & 0.457 \\
\hline Be promoted & 1.049 & 0.335 & Positive & 0.680 & 0.302 \\
\hline Go to the beach & 1.055 & 0.342 & Positive & -0.338 & 0.628 \\
\hline
\end{tabular}

Table 1 (continued)

\begin{tabular}{|c|c|c|c|c|c|}
\hline \multirow[b]{2}{*}{$\begin{array}{l}\text { Be unexpectedly upgraded } \\
\text { to first class }\end{array}$} & \multicolumn{3}{|c|}{$\begin{array}{l}\text { Event } \\
\text { valence }\end{array}$} & \multicolumn{2}{|c|}{$\begin{array}{l}\text { Event } \\
\text { significance }\end{array}$} \\
\hline & 1.062 & 0.321 & Positive & 0.137 & 0.567 \\
\hline Get a raise & 1.065 & 0.310 & Positive & 0.563 & 0.323 \\
\hline Play in the park with your child & 1.068 & 0.408 & Positive & 0.436 & 0.598 \\
\hline Get a new puppy & 1.073 & 0.407 & Positive & 0.524 & 0.576 \\
\hline Get a paid internship & 1.073 & 0.293 & Positive & 0.501 & 0.404 \\
\hline Go on a vacation & 1.090 & 0.333 & Positive & 0.230 & 0.464 \\
\hline Spend a holiday with family & 1.091 & 0.469 & Positive & 0.723 & 0.439 \\
\hline Win a new Porsche & 1.098 & 0.391 & Positive & 0.519 & 0.732 \\
\hline Get an unexpected vacation & 1.114 & 0.310 & Positive & 0.401 & 0.445 \\
\hline $\begin{array}{l}\text { Lay in a hammock overlooking } \\
\text { the beach }\end{array}$ & 1.153 & 0.385 & Positive & -0.159 & 0.662 \\
\hline Travel to a different country & 1.159 & 0.354 & Positive & 0.563 & 0.491 \\
\hline $\begin{array}{l}\text { Go to a concert of your } \\
\text { favorite musician }\end{array}$ & 1.163 & 0.337 & Positive & 0.518 & 0.496 \\
\hline $\begin{array}{l}\text { Spend valuable time with } \\
\text { close friends }\end{array}$ & 1.170 & 0.302 & Positive & 0.659 & 0.419 \\
\hline Get a large bonus at work & 1.179 & 0.291 & Positive & 0.704 & 0.356 \\
\hline Win a free vacation & 1.181 & 0.286 & Positive & 0.513 & 0.389 \\
\hline Get a week of paid vacation & 1.181 & 0.306 & Positive & 0.411 & 0.460 \\
\hline Be hired for a well paid job & 1.186 & 0.273 & Positive & 0.761 & 0.369 \\
\hline $\begin{array}{l}\text { Get a free plane ticket to } \\
\text { go anywhere }\end{array}$ & 1.258 & 0.347 & Positive & 0.647 & 0.432 \\
\hline Get a doctorate degree & 1.273 & 0.326 & Positive & 1.046 & 0.385 \\
\hline $\begin{array}{l}\text { Receive enough money to } \\
\text { satisfy all of your desires }\end{array}$ & 1.286 & 0.373 & Positive & 0.877 & 0.560 \\
\hline Be hired for your ideal job & 1.295 & 0.297 & Positive & 0.914 & 0.385 \\
\hline Get a perfect score on a test & 1.295 & 0.269 & Positive & 0.550 & 0.476 \\
\hline Get engaged & 1.298 & 0.419 & Positive & 1.021 & 0.345 \\
\hline $\begin{array}{l}\text { Be accepted into your ideal } \\
\text { school }\end{array}$ & 1.302 & 0.273 & Positive & 0.988 & 0.326 \\
\hline Win a Nobel prize & 1.319 & 0.330 & Positive & 1.114 & 0.478 \\
\hline Watch your child graduate & 1.321 & 0.408 & Positive & 1.106 & 0.310 \\
\hline Win a million dollars & 1.328 & 0.352 & Positive & 0.880 & 0.540 \\
\hline Watch your child get married & 1.331 & 0.358 & Positive & 1.178 & 0.350 \\
\hline $\begin{array}{l}\text { See your child get accepted into } \\
\text { their ideal school }\end{array}$ & 1.335 & 0.366 & Positive & 1.056 & 0.413 \\
\hline $\begin{array}{l}\text { Watch your child walk for the } \\
\text { first time }\end{array}$ & 1.340 & 0.333 & Positive & 1.112 & 0.342 \\
\hline Win millions of dollars & 1.347 & 0.354 & Positive & 0.932 & 0.471 \\
\hline Fall in love & 1.353 & 0.370 & Positive & 1.091 & 0.406 \\
\hline Graduate college & 1.356 & 0.254 & Positive & 1.106 & 0.305 \\
\hline Get married & 1.367 & 0.427 & Positive & 1.128 & 0.388 \\
\hline Accomplish a life goal & 1.369 & 0.267 & Positive & 1.102 & 0.366 \\
\hline Find your ideal significant other & 1.387 & 0.276 & Positive & 1.100 & 0.362 \\
\hline Get a free college education & 1.486 & 0.277 & Positive & 1.045 & 0.437 \\
\hline Cure cancer & 1.502 & 0.359 & Positive & 1.386 & 0.310 \\
\hline
\end{tabular}

\section{References}

Bar-Haim, Y., Kerem, A., Lamy, D., \& Zakay, D. (2010). When time slows down: The influence of threat on time perception in anxiety. Cognition and Emotion, 24(2), 255-263.

Bayer, M., Sommer, W., \& Schacht, A. (2012). P1 and beyond: functional separation of multiple emotion effects in word recognition. Psychophysiology, 49(7), 959-969.

Beck, A. T. (1970). Depression: Causes and Treatment. Philadelphia: University of Pennsylvania Press. 
Beck, A. T., Steer, R. A., \& Brown, G. (1996). BDI-II, Beck depression inventory: manual. San Antonio: Psychological Corp.

Bertsch, K., Böhnke, R., Kruk, M. R., \& Naumann, E. (2009). Influence of aggression on information processing in the emotional Stroop task-an event-related potential study. Frontiers in Behavioral Neuroscience, 3, 28.

Brugha, T., Bebbington, P., Tennant, C., \& Hurry, J. (1985). The List of Threatening Experiences: A subset of 12 life event categories with considerable long-term contextual threat. Psychological Medicine, 15, 189-194.

Cabeza, R., Ciaramelli, E., Olson, I. R., \& Moscovitch, M. (2008). The parietal cortex and episodic memory: an attentional account. Nature Reviews Neuroscience, 9(8), 613-625.

Cohen, D. J., \& Blanc-Goldhammer, D. (2011). Numerical bias in bounded and unbounded number line tasks. Psychonomic Bulletin \& Review, 18(2), 331-338.

Cohen Kadosh, R., \& Walsh, V. (2009). Numerical representation in the parietal lobes: Abstract or not abstract? Behavioral and Brain Sciences, 32, 313-373.

Compton, R. J., Banich, M. T., Mohanty, A., Milham, M. P., Herrington, J., Miller, G. A., ... \& Heller, W. (2003). Paying attention to emotion. Cognitive, Affective, \& Behavioral Neuroscience, 3(2), 81-96.

Denny, E. B., \& Hunt, R. R. (1992). Affective valence and memory in depression: Dissociation of recall and fragment completion. Journal of Abnormal Psychology, 101(3), 575.

Dobson, A., Smith, N., \& Pachana, N. (2005). Some problems with lifeevent lists and health outcomes. International Journal of Behavioral Medicine, 12(3), 199-205.

Donoghue, H. M., Traviss-Turner, G. D., House, A. O., Lewis, H., \& Gilbody, S. (2016). Life adversity in depressed and non-depressed older adults: A cross-sectional comparison of the brief LTE-Q questionnaire and life events and difficulties interview as part of the CASPER study. Journal of Affective Disorders, 193, 31-38.

Droit-Volet, S., Fayolle, S. L., \& Gil, S. (2011). Emotion and time perception: effects of film-induced mood. Frontiers in Integrative Neuroscience, 5, 33 .

Dudley, R., O'Brien, J., Barnett, N., McGuckin, L., \& Britton, P. (2002). Distinguishing depression from dementia in later life: a pilot study employing the Emotional Stroop task. International Journal of Geriatric Psychiatry, 17(1), 48-53.

Eckhardt, C. I., \& Cohen, D. J. (1997). Attention to anger-relevant and irrelevant stimuli following naturalistic insult. Personality and Individual Differences, 23(4), 619-629.

Einstein, A. (1907). 252 The relativity principle. Jahrbuch der Radioaktivitfit and Elektronik, 4, 411-462.

Frühholz, S., Jellinghaus, A., \& Herrmann, M. (2011). Time course of implicit processing and explicit processing of emotional faces and emotional words. Biological Psychology, 87(2), 265-274.

Garner, W. R. (1976). Interaction of stimulus dimensions in concept and choice processes. Cognitive Psychology, 8(1), 98-123.

Gilboa-Schechtman, E., Revelle, W., \& Gotlib, I. H. (2000). Stroop interference following mood induction: Emotionality, mood congruence, and concern relevance. Cognitive Therapy and Research, 24(5), 491-502.

Gotlib, I. H., \& McCann, C. D. (1984). Construct accessibility and depression: An examination of cognitive and affective factors. Journal of Personality and Social Psychology, 47(2), 427.

Holmes, T., \& Rahe, R. (1967). The social readjustment rating scale. Journal of Psychosomatic Research, 5(1), 213-218.

Kensinger, E. A., \& Corkin, S. (2003). Memory enhancement for emotional words: Are emotional words more vividly remembered than neutral words? Memory \& Cognition, 31(8), 1169-1180.
Lecci, L., \& Cohen, D. J. (2007). Altered processing of health threat words as a function of hypochondriacal tendencies and experimentally manipulated control beliefs. Cognition and Emotion, 21(1), 211-224.

Lecci, L., \& Cohen, D. J. (2002). Perceptual consequences of an illnessconcern induction and its relation to hypochondriacal tendencies. Health Psychology, 21(2), 147.

Lewis, V. E., \& Williams, R. N. (1989). Mood-congruent vs. mood-statedependent learning: Implications for a view of emotion. Journal of Social Behavior and Personality, 4(2), 157-171.

Mackay, D. G., Shafto, M., Taylor, J. K., Marian, D. E., Abrams, L., \& Dyer, J. R. (2004). Relations between emotion, memory, and attention: Evidence from taboo Stroop, lexical decision, and immediate memory tasks. Memory \& Cognition, 32(3), 474-488.

Malhi, G. S., Lagopoulos, J., Owen, A. M., Ivanovski, B., Shnier, R., \& Sachdev, P. (2007). Reduced activation to implicit affect induction in euthymic bipolar patients: an fMRI study. Journal of Affective Disorders, 97(1), 109-122.

Mathews, A., \& MacLeod, C. (1985). Selective processing of threat cues in anxiety states. Behaviour Research and Therapy, 23(5), 563-569.

McCloskey, M., \& Macaruso, P. (1995). Representing and using numerical information. American Psychologist, 50(5), 351.

Mitterschiffthaler, M., Williams, S., Walsh, N., Cleare, A., Donaldson, C., Scott, J., \& Fu, C. (2008). Neural basis of the emotional Stroop interference effect in major depression. Psychological Medicine, 38(02), 247-256.

Niedenthal, P. M., Halberstadt, J. B., \& Setterlund, M. B. (1997). Being Happy and Seeing "Happy": Emotional State Mediates Visual Word Recognition. Cognition and Emotion, 11(4), 403-432.

Oliveri, M., Vicario, C. M., Salerno, S., Koch, G., Turriziani, P., Mangano, R., ... \& Caltagirone, C. (2008). Perceiving numbers alters time perception. Neuroscience letters, 438(3), 308-311.

Price, R. B., Siegle, G., \& Mohlman, J. (2012). Emotional Stroop performance in older adults: Effects of habitual worry. The American Journal of Geriatric Psychiatry, 20(9), 798-805.

Pyszczynski, T., Holt, K., \& Greenberg, J. (1987). Depression, selffocused attention, and expectancies for positive and negative future life events for self and others. Journal of Personality and Social Psychology, 52(5), 994-1001.

Richards, A., French, C. C., Johnson, W., Naparstek, J., \& Williams, J. (1992). Effects of mood manipulation and anxiety on performance of an emotional Stroop task. British Journal of Psychology, 83(4), 479-491.

Sarason, I., Johnson, J., \& Siegel, J. (1978). Assessing the impact of life changes: Development of the Life Experiences Survey. Journal of Consulting and Clinical Psychology, 46(5), 932-946.

Shevrin, H., Panksepp, J., Brakel, L. A., \& Snodgrass, M. (2012). Subliminal affect valence words change conscious mood potency but not valence: is this evidence for unconscious valence affect? Brain Sciences, 2(4), 504-522.

Squire, L. R. (2004). Memory systems of the brain: a brief history and current perspective. Neurobiology of Learning and Memory, 82(3), 171-177.

Stenberg, G., Wiking, S., \& Dahl, M. (1998). Judging words at face value: Interference in a word processing task reveals automatic processing of affective facial expressions. Cognition \& Emotion, 12(6), $755-782$.

Walsh, V. (2003). A theory of magnitude: common cortical metrics of time, space and quantity. Trends in Cognitive Sciences, 7(11), 483488.

Williams, J. M. G., Mathews, A., \& MacLeod, C. (1996). The emotional Stroop task and psychopathology. Psychological Bulletin, 120(1), 3. 